\title{
A cooperação entre professores e alunos no estudo do direito ( $\left.{ }^{*}\right)$
}

\section{A. de Almeida Júnior}

Quero interpretar ao pé da letra o título desta cerimônia: "aula inaugural". Endereço-me, pois, não aos meus eminentes colegas, cuja honrosa presença neste recinto vem menos da curiosidade de ouvir-me do que das imposições da liturgia escolar; mas aos estudantes da Faculdade, e, entre êles, de maneira particularmente afetuosa, aos jovens do primeiro ano. Previno, entretanto, que mesmo em matéria de aula inaugural já me sinto demasiado veterano para mudar de estilo; e assim, em lugar dêsse título pomposo, dou preferência ao seu sinónimo do linguajar acadêmico. Ter-se-á, em suma, um "cavaco" inaugural.

\section{ACUSAÇões CONTRA A FACULDADE - O ANACRONIS- MO DO ENSINO}

Haveis de ter ouvido, aí por fora, murmurar da nossa Faculdade. Parece mesmo de bom tom, e no fluxo normal da tradição, alvejá-la de vez em quando com os dardos da critica. Entre os defeitos que se lhe apontam, sobreleva, pela reiteração com que o fazem, o do anacronismo das suas doutrinas. Neste período de civilisação em mudança (dizem alguns), as formas de governo passam por alterações radicais: havendo a experiência de mais de cem anos

(*) Aula inaugural dos cursos da Faculdade de Direito da Universidade de São Paulo, a 24 de março de 1942. 
desmentido as esperanças de JeFFERson na sagacidade política do povo, a democracia reclama retoques profiláticos, sem os quais continuarão a brotar pretextos para os regimes de força; mas a Faculdade, fiel ao pensamento burguês de 1830, ainda se satisfaz com o formalismo das urnas. A economia liberal do século passado (comentam outros) está morrendo empanzinada: um direito novo, mais equitativo, dá agora funções sociais à propriedade e ampara com a força do Estado a fraqueza do proletário; mas a Faculdade, cega e surda à evolução, continua a prégarar o individualismo espenceriano. Sob a pressão de ideias adiantadas do direito criminal (acresenta-se ainda), a "pena" da velha escola se individualiza, torna-se indeterminada, perde o carater retributivo, cedendo lugar à medida de segurança: todos o sabem, nas associações científicas e na imprensa, nos tribunais e nas ruas; todos, menos a Faculdade. $O$ texto legal, outróra rígido, casuístico, formal, modifica-se para o preceito genérico e flexível, capaz, sob a inspiração penetrante do juiz, de afeiçoar-se às multiformes situações concretas; mas a Faculdade, indiferente aos impulsos renovadores, continua a venerar "a letra que mata". A realidade, enfim (resumem os criticos, numa frase traduzida do francês) a realidade exsuda o direito; mas a Faculdade, ingênua ou metafísica, insiste em lecionar o contrário: para ela, é o direito que fabrica a realidade.

Seriamos dêsse modo, meus caros amigos, uns abantesmas do passado, que diáriamente nos reuniriamos neste casarão mal assombrado, com o fim de apavorar a juventude. De sorte que o estudante que aqui entre, para a sua excursão arqueológica de cinco anos, faz um pouco o papel do explorador CARTER esquadrinhando as galerias de Tutancamen; e quando de nós se aproxime, na tentativa de decifrar o pensamento dos faraós, deve resguardar-se da poeira numulítica e manusear-nos de longe, com as pontas dos dedos. 


\section{ADVERTÊNCIA PREVIA}

Mas, antes de prosseguir, cabe uma advertência. Parecerá esdrúxulo que justamente ao professor de Medicina Legal tenha sobrevindo o prurido de afrontar esta matéria. Por que não se contenta êle com as suas equimoses, os seus infanticidios, as suas paranóias? Seria, senão mais interessante, pelo menos mais prudente!

Quanto a isso, socegai, meus caros amigos: conhecendo, como conheço, o meu lugar nesta casa, não sairei do "visum et repertum". Contarei simplesmente o que tenho visto, e só opinarei sôbre coisas de minha alçada. Uma vantagem, entretanto, se me há de conceder, e é a de que, no posto marginal em que me acho, mais insuspeitamente que os outros posso observar e apreciar a correnteza das águas.

Demais, êste dia inaugural, em que convém avivar entre vós e vossos mestres os vínculos de simpatia, e em que deve abrir-se em vosso espírito, em relação a nós, um largo crédito de confiança, é, segundo entendo, o mais adequado para prevenir-vos contra certas acusaçōes imputadas ao instituto que elegestes para completar a vossa formação escolar.

Não; não encontrareis aqui o decantado frigorífico de idéias. Vejo, há treze anos, cada um dos meus eminentes colegas, de sismógrafo à vista, constantemente preocupado em registrar os mínimos abalos na opinião jurídica contemporânea; observo-lhes a preocupação de surpreender os movimentos mais sutís dos vanguardeiros do direito; assistolhes ao esforço no sentido de penetrar, de criticar e de difundir novas doutrinas, venham da Europa ou da América, sejam extrangeiras ou nacionais. Por que, então, falar em anacronismo?

A história da fossilização do ensino jurídico não passa de um lugar comum da retórica nacional. Proveitosa apenas como tema de ensaio literário, oferece, é certo, a vantagem de aguerrir a mordacidade glóssica da juventude; 
serve de inspiração a bachareis ocasionalmente sacudidos por espasmos de vocação professoral; funciona, às vezes, como alvo imaginário dos políticos, nos seus vôos de mergulho sôbre o território do direito. Só isso, e nada mais.

\section{A FALTA DE ENSINo PRÁtico}

Mas prossigamos na análise das acusações. Diversas outras críticas reduzem-se a dois itens: $10^{\circ}$ ) falta de preocupação com os objetivos profissionais do curso; $2 .^{\circ}$ ) impropriedade nos métodos e processos de ensino.

Quanto aos objetivos, o problema, que é antigo, foi há pouco re-examinado em várias universidades norte-americanas. O que se apura, nesta revisão e classificação de velhos e de novos depoimentos, fortalecidos todos pela observação do próprio ambiente brasileiro, é que em nenhuma época da história o curso de direito se satisfez com os intúitos puramente forenses. Além de se esgalharem em múltiplos sentidos as carreiras a que abre ingresso, eleva êle, quando no seu feitio universitário típico, a estudos e investigações jurídico-sociais desinteressados. $\mathrm{E}$ tanto por êstes últimos quanto pelos de formação profissional escrita, as Faculdades jurídicas têm sido ferteis sementeiras da "élite" cultural de cada país e a formadora mais assídua dos homens responsáveis pelas culminâncias do pensamento nacional.

Correriamos, portanto, um risco perigoso se quizéssemos, com a preocupação de receituários e de exercícios técnicos, asfixiar os estudos doutrinários.

Acresce ainda que, mesmo na escola jurídica exclusivamente profissional, que porventura exista, se é defeito haver ensino básico desacompanhado de prática, maior mal resultaria da situação inversa, isto é, se houvesse prática sem teoria. Lord Brougham (citado por JoÃo Mendes) escrevia, na Inglaterra: "o advogado e o juiz, formados sem base filosófica, resolvem as dificuldades por precedentes, 
sem revelar qualquer argumento fundado nos princípios da ciência das leis". E Blackstone advertia: “o homem assim educado para o fôro verá que, se a prática é tudo o que se lhe ensinou, é tambem tudo o que êle saberá; se não estiver instruido dos elementos e dos principios sôbre os quais se fundam as regras práticas, a menor variante nas relações jurídicas o perturbará e o extraviará. Jamais poderá êle pretender construir, e raramente poderá compreender um argumento deduzido do espirito das leis e dos fundamentos naturais da justiça".

Portanto, meus senhores, no passado como no presente, a experiência proclama aos professores de direito: ensinai a prática, sem vacilações, quer a título de treino, quer como processo de melhor compreensão da doutrina; mas realçai e fortalecei os princípios, pois sem êles não formareis juristas e sim, quando muito, profissionais de horizonte limitado, escravos do empirismo.

\section{IMPROPRIEDADES DIDÁTICAS}

Passemos, entretanto, à outra acusação: a impropriedade das técnicas pedagógicas da Faculdade.

Para melhor examinar o problema, iniciei um serviço de recenseamento bibliográfico. Recenseamento que responda, de começo, a esta simples indagação: quantos, entre os nossos professores, têm manifestado, publicamente, preocupações a respeito das técnicas de ensino? Para verificálo, ando lendo discursos de posse, artigos de jornal ou de revista, aulas inaugurais, orações de paraninfo, relatórios. Estou ainda no princípio, e já responderam à chamada, entre os mortos, Pedro Lessa, João Mendes Júnior, Amâncio de Carvalho, Alcântara Machado; e entre os vivos, João arruda, Spencer Vampré, Sampaio Doria, Valdemar Ferreira, Vicente Ráo, Gabriel de Rezende Filho, Jorge Americano, NoÉ Azevedo... Relação certamente parcialíssima. Quando ela se completar, ter-se-á interessante matéria prima com 
que se escreva um ensaio sobre as doutrinas pedagógicas da Faculdade de Direito de São Paulo. Por agora, entretanto, é ela mais do que suficiente para desmentir os que dizem que aqui ninguem cogita de técnica didática.

\section{OS MéTODOS E O ENSINO}

Embora os métodos sejam essencialmente dois - a indução e a dedução - certas nuanças e combinações, em uso nos cursos de direito, permitem distinguir vários tipos, aos quais, por comodismo, atribuiremos um rótulo de nacionalidade:

1..$^{\circ}$ O método anglo-americano antigo, ou sistema casuístico, herdado da Escola das Remissões e Casos Julgados.

2. ${ }^{\circ}$ O método anglo-americano moderno, tambem chamado "de laboratório", no qual os casos forenses são analisados, não mais a título de "precedentes", mas como pontos de partida para a indução de princípios.

3. ${ }^{\circ}$ O método germânico, dedutivo, pois desce da doutrina para os fatos.

4..$^{\circ} \mathrm{O}$ método francês, ou exegético, que toma por base o texto da lei.

5..$^{\circ}$ O método italiano, preconizado por CHIRoni: é uma espécie de aliança franco-germânica, pois combina o exame dos textos com o estudo sistemático das doutrinas.

Ora bem. Das palavras dos mestres da nossa Faculdade - João Mendes ou Vicente Ráo, Gabriel de Rezende Filho ou Jorge Americano - o que se infere é que nenhum apoia o obsoleto sistema casuístico, ainda em uso em escolas norteamericanas, nem nutre simpatias pelos dois métodos exclusivistas, 'de dedução ou de exegése. Todos preferem o plástico e fecundo ecletismo de CHironi. E vão alem: exigem, a título de complemento, conforme declara o prof. Vicente RÁo, "uma sistemática verificação da correspondência, ou 
não, dos diversos institutos jurídicos, com as condições sociais próprias dos povos a que se destinam."

Estamos, pois, inteiramente atuais em nossos métodos. Atuais e vanguardeiros, desde que insistimos pelo confronto incessante entre as instituições e o meio. Efetivamente, os princípios jurídicos e as leis, num flagrante paralelismo com os reagentes químicos ou biológicos, não atuam só por suas forças intrínsecas, mas também em função das influências ambientais. O professor de direito (diz Jorge AmeRICANo) estuda "sob a pressão dos fatos sociais", que o obrigam, "a cada passo, a refazer o exame das suas noções básicas". "A realidade (recordemos ainda uma vez) a realidade exsuda o direito."

Daí vem que em toda parte se pedem aos cursos jurídicos investigações sociais cada vez mais profundas, um contacto cada vez mais íntimo com o mundo real. Não se retraiam êles dentro de seus muros, a edificar repúblicas de Platão, nem adotem, para não ver os rudes embates da vida, o conhecido expediente do avestruz. Ao contrário, é do seu dever observar a sociedade, e, procurando nos fatos circunjacentes as raízes, a atmosfera, os frutos dos princípios e das leis, submetê-los a uma análise rigorosamente objetiva e imparcial. Dar-se-á, assim, mais substância ao ensino, e, do mesmo passo, fugir-se-á desta grave acusação que às vezes se nos lança: a de ineficiência social. Afirma Gustavo Aron que as Faculdades de Direito têm repugnância em atuar sobre o mundo exterior, ou em manifestar opiniões públicamente, donde (em França, pelo menos) sua nula influência na formação política da juventude.

Ainda neste particular estamos isentos de pecado. A Faculdade de Direito de São Paulo, pela coragem cívica dos seus professores e alunos, já inscreveu páginas de característica independência na história brasileira, e dela não se dirá que jamais tenha esposado a teoria de certo ministro alemão, segundo a qual só é verdade perante a ciência, só é justiça perante os tribunais aquilo que favoreça a política nazista. 


\section{OS PROCESSOS DE ENSINO E O INTEREASSE}

Mas deixemos os métodos e digamos duas palavras a respeito da sua execução prática. Em outros termos, conversemos sôbre processos didáticos.

Há uma pedra de toque fidelíssima para se saber se um processo de ensino é bom ou mau: é bom o processo que desperta o interêsse do aluno pela matéria em estudo; é mau o que não desperta êsse interêsse. Porque do interêsse vem a cooperação efetiva do estudante no trabalho proposto, realizando-se pedagógicamente aquilo que Bovet chamou de "escola ativa".

Procuremos, portanto, processos que assegurem o interêsse pelo nosso ensino; tentemos a "escola ativa" na Faculdade de Direito.

Contudo, também os preceitos didáticos precisam ser contrasteados com as oposições da realidade.

Sabe-se que, não obstante as provas vestibulares e mesmo as provas de curso, nem todos os alunos que recebemos no começo de cada ano letivo possuem a feição de espírito, o nível de inteligência, o grau de cultura propedêutica indispensáveis ao gosto pelas disciplinas jurídicas. Atráves das malhas desiguais da nossa rêde de exames, escapam estudantes cujo tipo mental é absolutamente incompatível com as abstrações e a reflexão exigidas pelo curso de direito. Interessá-los no estudo? Mas como? Pois se são êles (depõe o prof. João Arruda) se são êles que "jogam dados enquanto o mestre preleciona, ou apostam sôbre o lugar do rosto onde o professor porá primeiro a mão"! São êles (acrescento eu) que se utilizam da hora e do lugar da aula para ler, entre sonolentos bocejos, os jornais matutinos. São êles que, por indiferença ao argumento, ressonam durante a preleção. São êles, afinal, que fraudam a frequência ou "colam" nos exames. Interessá-los no estudo? Bem conheço a recomendação evangélica que diz: o passo do pastor deve medir-se pelo das mais pequeninas ovelhas. Mas o pastor não pode sacrificar a marcha coletiva, só por- 
que no seu rebanho clandestinamente se insinuaram alguns carneiros paralíticos. Se nos guiassemos por êstes, fugiriamos aos propósitos da missão a que nos comprometemos de formar juristas - e, falseariamos uma das funções primordiais da escola - a de órgão de seleção e redistribuição social.

Por isso, precisamos escolher cuidadosamente o nosso rebanho, ou, melhor, os nossos colaboradores juvenís de cada ano. Por isso, ainda, e pela conciência que temos de que as nossas aulas não podem, em matéria de sedução, competir com as modernas distrações mundanas, somos forçados a juntar, ao interêsse intrínseco pela disciplina em estudo, o interêsse extrínseco de fugir à reprovação. Pois na escola superior, mais do que em qualquer outra, cada participante do fenômeno didático há de contribuir com a sua parcela específica: se ao professor compete tornar o trabalho interessante e proveitoso, cabe ao aluno, por seu nível mental, sua cultura e seu esforço, oferecer condições de receptividade que possibilitem o ensino.

\section{A PRELEÇão e SEUS TIPOS}

O principal, senão exclusivo processo didático usado na Faculdade é, por enquanto, a preleção, e nisso não há muito que extranhar, dada a natureza dos nossos cursos. De fato, a palavra constitue o melhor instrumento para comunicar ou sugerir ideias, tanto que as tentativas, já postas em prática, de explicar noções jurídicas mediante gráficos, nos parecem de um primarismo insuportável. A expressão verbal, ductil e matizada, representa efetivamente a força com que, na maioria das vezes, o homem civilizado comove ou estimula, persuade ou convence, separa ou harmoniza. Demais, está ela para o jurista como para o cirurgião está o bisturí: é a sua ferramenta. Só há vantagem, portanto, em que o estudante se familiarize com o mundo dos vocábulos e consiga apreender-lhe os recursos e limitações. 
Dois extremos de preleção distinguio em nossa Faculdade o prof. NoÉ Azevedo, segundo conta em seu discurso de posse. Um é o da aula (diz êle) "magistralmente declamada" com que "empolgava os primeiros-anistas" êsse mestre ilustre, glória do magistério jurídico brasileiro, o prof. Reinaldo Porchat. O outro é "a argumentação simples, clara, sedutora daquele incomparável causeur que foi Gama Cerqueira". Ora, ninguem negará a eficiência dos dois tipos, desde que cada qual condiga com o temperamento e os recursos do professor respectivo. Suponho, entretanto, que perde terreno, de ano para ano, a lição declamada, materializando-se mesmo essa evolução no progressivo desaparecimento das chamadas "cátedras", já substituidas, na maioria, por singelas mesas, que convidam menos aos arroubos de eloquência.

Na preleção, o aluno apenas ouve; e apenas ouvir pode ser em si mesmo interessante. "Em meu tempo (conta o prof. Jỗo ARruda) fechávamos cuidadosamente as portas da sala, para que ouvissemos as palavras preciosíssimas do prof. Ramalho..." Mas tambem pode não ser! Existem, por isso, artifícios que pretendem melhorar o interêsse pela aula. Um deles, preconizado pela Universidade de Coimbra, é o diálogo, à moda de Sócrates. Considere-se, porem, a diversidade de situações. As turmas do filósofo grego nunca tiveram, como as nossas, oitenta a cem alunos, nem estava êle obrigado a desenvolver, em sessenta aulas, um determinado programa. Acresce que a lição nada ganha só por ser dialogada. "A lição (escreve Lombardo Radice, o inspirador, na Itália, da grande reforma GENTrLE) a lição não logra valor didático porque seja dialogada ou expositiva, mas por sugerir problemas ou estimular a sua solução". Em outros termos, o mérito da pedagogia socrática está mais em Sócrates do que na pedagogia.

Melhor que o diálogo, embora de influência igualmente limitada, são as chamadas orais, ou os exercícios escritos com que alguns dos nossos professores costumam afugentar da aula os alunos preguiçosos. Alem de exercício para o estudante, e de coerção suplementar ao estudo, as chamadas 
orais (acentua o prof. Jorge Americano, aliás em outros termos) constituem uma espécie de sondagem pela qual de vez em quando procuramos verificar se estamos em rumo certo. Infelizmente, porém, a penúria de tempo durante o ano, nos impede de procurar apoio frequente nesses recursos pedagógicos.

\section{ENSINO OBJETIVO - AUTONOMIA DIDÁTICA}

Muito se fala de objetivação do ensino, mediante exame de casos reais ou pela apresentação de coisas e instituições relacionadas com as matérias do curso. Note-se desde logo que a escassez de objetivação é, nos cursos jurídicos, defeito universal. KarL Llevellyn, por exemplo, escreve, em maio de 1935: nas faculdades alemãs, a despeito de sucessivas reformas, o ensino permanece essencialmente teórico. No mesmo ano, a propósito da França e da Itália, dizia CARNELUTTI: "os nossos discípulos se tornam doutores sem jamais terem visto um caso vivo de direito". E sugeria, por isso, entre outras coisas: "que não se ensine direito bancário sem mostrar aos alunos um banco, nem direito marítimo ou penal sem visitar um porto ou uma penitencíaria, nem direito processual sem havê-los feito percorrer salas de audiências e cartórios..."

No sentido da objetivação, alguns ensaios já se fazem em nossa Faculdade, e neste particular, se me abstenho de pormenores, é para não invadir a economia interna de cada disciplina. Aqui, convém, aliás, uma importante advertência : sejam quais forem os métodos e processos que se advoguem, devem, em sua escolha, permanecer livres os professores, como livres devem ser seus programas e doutrinas. Essa autonomia é tão indispensável à função pioneira do ensino superior, que não poderiamos permitir que ela nos escapasse. Foi árdua a sua conquista. Em 1826 (refere o prof. Vicente Ráo), o deputado Lino Coutinho defendia a opinião de que ao poder legislativo deveria competir indicar aos mestres de direito os compêndios, as dou- 
trinas e os métodos de ensino. "Os lentes (exclamava o deputado) são como as amas de leite; toda ama de leite diz que o seu leite é bom; mas quem é que decide? É a ama? Não, é o médico". Felizmente, a ideia malogrou, de sorte que nesta Faculdade, outróra como hoje, no Império ou na República, - e usando ainda a grosseira comparação de LiNo Coutinho - o nosso leite espiritual vem sendo oferecido à juventude inteiramente isento das manipulações oficiais.

\section{CONTACTO ENTRE PROFESSORES E ALUNOS - OS SEMINÁRIOS}

Acabamos de citar vários recursos do arsenal pedagógico: a preleção, o diálogo, a chamada oral, o exercício escrito, a objetivação. Mas nenhum será realmente eficaz se não promover a cooperação ativa do estudante. Enquanto apenas trabalha a inteligência do professor, não há ensino. Este só começa no momento em que entra em ação a inteligência do aluno. Escutai o comentário do prof. GabrieL. dE Rezende FiLHo, nas seguintes palavras, inspiradas pelo mais moderno pensamento pedagógico: "Fato é (diz êle) que o ensino que não estimula, que não incentiva, que não desenvolve a faculdade de iniciativa dos alunos e nem favorece a capacidade de cada um, no sentido da crítica pessoal, da observação, do raciocínio e da generalização, é evidentemente um ensino deficiente e vazio".

Atentai, porem, para as condições de ordem prática. Como poderiamos atingir êsse magnífico ideal, senão pelo contacto frequente e direto do professor com o discípulo? $\mathrm{E}$ como alcançar êsse contacto através unicamente das aulas de preleção?

Vêde o que se passa nas nossas escolas médicas e na: Faculdade de Ciências. Alí, o convívio espiritual entre estudantes e mestres é favorecido por duas circunstâncias. Primeiro, a relativa longura do dia letivo dos alunos, o qual tem, naquelas escolas, pelo menos seis horas de duração, enquanto que na Faculdade de Direito não passa, em regra, 
de duas ou três horas. Depois, a vantajosa proporção numérica entre docentes e discentes. Somados professores e assistentes, existe, na Escola Paulista de Medicina, um docente para cada três alunos; na Faculdade de Medicina da Universidade, um docente para cada cinco alunos; na Faculdade de Ciências, um docente para cada seis alunos. Mas aqui, na Faculdade de Direito, somos um professor para cada grupo de quarenta alunos. Se, pois, quizéssemos adotar (como já foi lembrado) aulas práticas e exercícios de clínica análogos aos da Faculdade de Medicina, o nosso corpo docente, agora de vinte e cinco professores, teria de elevar-se a duzentos elementos. Duzentos, parece que seria excessivo. Entretanto, nas condições atuais, a ambicionada articulação, traduzida, por exemplo, pela organização sistemática de seminários, se torna práticamente impossível. Eis porque dei o meu apláuso, há cêrca de três anos, à proposta do prof. VAMpré, no sentido de criar-se, para a Faculdade, um corpo de assistentes. A instituição da assistência, que já em 1911 o governo português reconhecia superior à da livre docência, viria preencher duplo objetivo, pois, além de dar a cada cadeira um ou mais auxiliares didáticos, constituiria a melhor sementeira para o cultivo de novos professores.

Mais um reparo, entretanto. A promissora orientação. a que aludimos depende ainda de um outro fator - e êsse tão primordial, tão importante, que a êle vamos consagrar a última parte da nossa aula. Trata-se do fator aluno. Continuemos, pois, a analisar os problemas práticos do ensino, mas agora convergindo o nosso olhar para o sector dos. estudantes.

\section{O CURSO SECUNDÁRIO - TROTE E CABALA - A FREQUENCIA}

Afirma-se que a educação de cada homem deve principiar duzentos anos antes do seu nascimento. Em relação ao acadêmico de direito, vamos ser menos exigentes: vamos. 
pedir que comece no curso secundário. De fato, cincoenta por cento, ou mais, dos defeitos achados nos trabalhos dos nossos alunos, do primeiro ao quinto ano, provêm do ginásio. Baste notar que, ao corrigir as provas de Medicina Legal, meu consumo de lapis vermelho é quase nada para a matéria que leciono, é quase tudo para os erros de português.

Mas de que vale falar, hoje, da escola secundária? Bôa ou má, ela já nos entregou os estudantes, e agora o que nos cumpre é enfrentar uma situação de fato. Comecemos, pois, a partir da própria Faculdade.

Ao ingressar aqui, é o aluno recebido por duas forças antagônicas: uma - a de repulsão - tem o nome de trote; outra - a de coesão - chama-se cabala eleitoral. Nos tempos idos, a primeira era a única a funcionar e funcionava em todo o seu agreste primitivismo. Parece, entretanto, que o trote da Faculdade de Direito está tomando feições menos repulsivas, e sublima-se graças ao maior polimento nos costumes. Cresce, por outro lado, a força de agregação representada pela cabala. Perguntareis, contudo, senhores estudantes: mas a que vêm, numa aula inaugural, estas referências à nossa conduta nos páteos e corredores? E que, meus amigos, aqueles dois institutos, alem de índices de um certo grau de cultura e até denunciadores, algumas vezes, de tipos psico-patológicos especiais, se prendem à formação moral e política do acadêmico, havendo, portanto, de um e de outro, muito que dizer. Mas não é esta a oportunidade. Passemos adiante.

Vamos à questão- da frequência. Nos termos da lei, a frequência é obrigatória. Calar, porem, a existência de fraudadores, seria tentar esconder um segredo de polichinelo. Certo dia, um aluno do quarto ano (notai bem: do quarto ano!) tomou o bonde em que eu viajava, sentou-se ao meu lado, e, depois de observar-me alguns momentos, não se conteve que não dissesse: “- Parece que eu já vi o senhor em algum lugar..." Pois êsse era dos tais que só se apresentam aqui nos dias de prova escrita, e isso mesmo em segunda chamada. $O$ problema da frequência vem sendo debatido desde 1826, e até hoje reina a discórdia em tor- 
no dele. Perante a lei atual, a matéria não comporta debate: é obrigatória a frequência, e dela não podem os alunos ser dispensados senão por nova lei. Mas a questão é outra: convirá mantê-la ou suprimí-la?

Se argumentarmos com os dados do senso superficial, e através da frieza da lógica, não há necessidade de frequência obrigatória. Os alunos estudarão onde quizerem; depois, por ocasião das provas, passarão os que souberem, serão reprovados os outros. E a função essencial da Faculdade se reduzirá à de banca de exame.

Entretanto, ocorrem argumentos que escapam ao senso superficial.

Em primeiro lugar, supor a existência de alunos que, sem o estímulo das aulas, se consagrem metódicamente ao estudo do direito, talvez não seja fantasia, mas anda perto. Há cerca de dois anos, submeti o fato a uma verificação interessante. Dei ao prof. Milton da Silva Rodrigues, especialista em estatistica aplicada à educação, as notas obtidas pelos meus alunos de Medicina Legal, nos dois exames parciais. Forneci-lhe, conjuntamente, a relação das faltas de cada um, e pedi-lhe que confrontasse as duas séries de informações. Pois o resultado foi demonstrativo: existe, entre a frequência e as notas de exame, senão paralelismo absoluto, pelo menos acentuadissima correlação.

A defesa da frequência livre baseia-se num pressuposto falso e práticamente incompativel com o sentimentalismo brasileiro: o da idoneidade do exame para, por si só, negar ou conceder diplomas. Quanto a isso, os exames em geral, os nossos em particular, erram lamentavelmente. Os nossos, então, sempre o fazem pela benevolência, pois nós professores (mesmo os mais afamados pela severidade), acabamos vencidos, recuando ante a força poderosa da "pressão sentimental" Com efeito, se são em número razoavel os que reprovam o estudante uma primeira vez, são poucos os que reprovam duas vezes, e raríssimos, se é que existem, os que o fazem três vezes, embora se tenha, de ano para ano, mantido inalterado o nível de ignorância do candidato. O que quer dizer que, além das aprovações por estudo (fe- 
lizmente as mais numerosas), e das eventuais aprovações por "cola", tambem as há por antiguidade.

Como explicar estas últimas? Como compreender que, a despeito de certas barreiras célebres existentes em cada Faculdade, chegue diplomar-se, de vez em quando, um ou outro analfabeto? Efeito, meus senhores, do clamor surdo mas incoercivel da opinião social, germinada nos meios escolares, transportada para o seio das famílias, e até veiculada pela imprensa; é a "pressão sentimental", à que cede, por fim, contagiado ou exausto, o próprio professor.

Aludo ao fato, para trazer novo argumento contra a idoneidade dos exames, e para acentuar a vantagem de a êles adicionarmos outros critérios de apreciação. E neste particular, como presunção de cultura, a frequência às aulas vale mais do que a ausência. E mais significativa ainda ela será, quando a simples presença passiva do estudante fôr substituida por sua cooperação ativa nos exercícios práticos, nos grupos de trabalho ou nas pesquizas.

\section{FREQUENCIA E ASSIMILAÇÃO SOCIAL}

Mas a frequência escolar apresenta importância igualmente grande se considerada do ponto de vista mais alto da socialização. Há, no convivio diuturno dos estudantes, uns com os outros, vigorosa força de assimilação social, que devemos acoroçoar. Nesse papel, sobreleva, em São Paulo, a função nacionalizadora da escola. Matriculam-se na Faculdade de Direito (e também nas outras escolas superiores) filhos de italianos, de portugueses, de espanhois, de sírios. de judeus, de japoneses... Uma verdadeira Babel! Fazêlos vir todos os dias passar algumas horas com os brasileiros de quatrocentos anos (porque tambem os há por ali), é, sem dúvida, cooperar para a sua assimilação sentimental e ideológica. Demais, em relação aos descendentes de estrangeiros, como em relação aos filhos das diversas regiões do intèrior do Estado, viciados todos por prosódias domésticas ou regionais, êsse atrito 'quotidiano, em que ouvem e falam li- 
vremente, e em que se submetem à crítica zombeteira dos colegas, é a melhor escola de homogeneização linguística que se lhes possa oferecer.

Em suma, meus senhores, e a despeito do meu liberalismo pedagógico, sou forçado a reconhecer que, nas nossas condições atuais, os argumentos favoráveis á frequência obrigatória valem mais que os argumentos contrários, e que, sopesados ainda os interêsses individuais de alguns e os interêsses gerais da coletividade, o instituto deve permanecer.

\section{POSTILA “VERSUS" LIVRO}

Considere-se, porem, não só a quantidade, mas tambem a qualidade da frequência. Conta Maurice Donnay que no Colégio de Jesuitas onde MoliÈre estudou, havia dois tipos de alunos: uns - os vulgares - amontoados até pelos degraus da escada, ouviam e tomavam notas; os outros - os da nobreza — só ouviam, não tomavam notas, pois para êsse mistér subalterno cada qual tinha o seu escriba. Suponho que a distinção continua, na Faculdade de Direito de S. Paulo: temos aqui alunos principes, que só ouvem (quando ouvem!), e alunos secretários, que escrevem para si e para os outros. E, assim, êsse ato tão .pessoal, tão avivador do interêsse, que é o de selecionar e registrar as suas próprias notas, se transforma em uma operação inexpressiva, estereotipada, sem quase nenhum alcance intelectual.

Daí nasce tambem um outro inconveniente: as célebres postilas. Não quero dizer mal dos nossos jovens estenógrafos, diversos dos quais se têm revelado moços de grande perseverança e estudantes fora do comum. Mas preciso opôr algumas restrições ao tradicional e generalizado uso das postilas. A certeza de que está ao seu lado um secretário diligente, a escrever tudo quanto diz o professor - inclusive as velhas anedotas, que cada ano se repetem - convida o aluno ao devaneio. Para que o esforço de prestar atenção, 
se dentro de poucos dias, no aconchego do seu quarto, terá êle a palavra do mestre reproduzida em folhetim? Para que vir à aula? Acresce que, por forçà de circunstâncias óbvias, são as postilas, algumas vezes, um repositório de disparates, que a nós, mestres, seus pais clandestinos, nos fazem rir de surpreza ou chorar de desespero. E o estudante acredita na postila como se fôra o Evangelho. Em exames finais, ouvem-se diálogos como êste: "— 0 senhor se enganou, não é assim. - Mas, senhor professor, é assim que está na postila! - Não importa, está errado. - Mas . eu poderei mostrar "E a gente percebe que o examinando gostaria de prolongar a discussão para dizer, afinal: "- Então, o senhor quer saber mais do que a postila!"

O peor de tudo, porem, é que a postila, com os serviços que presta, presta o grande desserviço de afastar do livro. $\mathrm{Na}$ postila vê o aluno o texto único, sagrado e intangivel do seu estudo: nela se contem tudo o de que êle precisa, e nada mais. Para que o livro? Sucede, por isso, que a maioria dos nossos discípulos deixam a Faculdade sem haver adquirido o segredo das investigações bibliográficas, o hábito da consulta direta, o amor à fidelidade das citações, - tudo tão necessário a qualquer intelectual, e particularmente ao jurista.

Sejamos justos: em matéria de leitura, estamos progredindo. Graças aos dados que me forneceu o diligente bibliotecário da casa, e aos cálculos que fiz, pude averiguar um fato significativo. Outrora, no trienio 1908-1910, cada aluno da Faculdade ia, em média, cinco vezes por ano à biblioteca; agora, no trienio 1939-1941, vai quinze vezes. Feitas, pois, as proporções entre matricula e consultas, e excluidos os simples leitores de jornais, a frequência à biblioteca triplicou, nos últimos trinta anos. Entretanto, vêde bem: apenas quinze vezes por ano, ou seja pouco mais de uma vez por mês, e isso tratando-se da mais rica e mais bem organizada coleção de livros jurídicos do país. E' ainda mesquinho. $E$ se formos rever, uma a uma, as fi- 
chas de consulta, certamente verificaremos que muito bacharel passou pelos cinco anos de curso sem sequer conhecer a nossa magnífica biblioteca.

\section{A FREQUênCIA AOS EXercicios práticos}

Ainda uma rabugice, meus caros amigos, e será a última. Louva-se a objetivação do ensino, fala-se em exercícios práticos, apontam-se as virtudes dos seminários. Está muito bem. Mas quando o professor resolve apelar nesse sentido para a cooperação dos alunos, a resposta fica muito aquem da espectativa. As queixas que, no particular, ouço algumas vezes dos meus colegas, seriam para desanimar, se nós, professores, tivessemos direito ao desânimo.

Costumo realizar, cada ano, oito a dez visitas a instituições de interêsse para os estudos médico-legais — visitas em regra acompanhadas de sugestivos exercícios práticos. Pois bem, dos duzentos alunos que compõem o quarto ano, quereis saber quantos comparecem? Nunca mais de vinte (salvo quando se trata de visita ao Juqueri)! Os outros cento e oitenta preferem ficar em casa, ou estão presos por seus empregos e ocupações.

Pretendi, há tempos, uma inovação: uma espécie de seminário à tarde, em tôrno de demonstrações práticas e da análise de laudos periciais. Para isso, convoquei os alunos que quizessem comparecer, marquei dia, lugar e hora, fiz todos os preparativos, e, quando chegou o momento da estréa, entrei solenemente na sala. Com grande decepção, vi apenas um rapaz (apenas um!) sentado diante da mesa do professor. Entretanto, nem por isso desisti. "Somos só dois, disse-lhe eu, mas vamos começar". O rapaz, então, muito assustado, se ergueu e disse: "O senhor me desculpe, eu não sou estudante, sou empregado da casa!” (“)

(*) Em 1942, todavia, a frequência às visitas e aos seminários de Medicina Legal melhorou notavelmente. 
E saber-se que, segundo afirmam os alunos, a Medicina Legal é uma das matérias mais interessantes do curso de direito!

\section{CONTACTO E COOPERAÇÃO}

Vamos porém encerrar êste demoradíssimo cavaco. A nós, professores da Faculdade, move-nos o desejo de que o nosso ensino seja bom. Por isso, conciente ou inconcientemente, por pedagogia ou por índole, cada qual se preocupa com fazê-lo interessante e proveitoso. Divergem, neste ponto, os critérios de apreciação, bem como o valor intrinseco dos expedientes postos em uso para interessar. Mas os propósitos coincidem, e isso já significa um grande passo no sentido da perfeição didática.

Todavia, por si só o nosso esforço não basta: é tambem indispensável o esforço do estudante, cujas diretrizes gerais de cooperação, ao menos no seu aspecto exterior, aí ficaram delineadas. De um lado, os contactos culturais: contacto com as arcadas e com as aulas; contacto com as lições, os mestres e os livros; contacto com os fatos jurídicos e sociais. De outro lado, a contribuição mais intelectual e própriamente ativa do estudante, representada pelo seu trabalho reflexivo, sua crítica e produção pessoal.

Outróra, nas escolas, alunos e mestres formavam duas hostes antagônicas, em estado de perptua beligerância. 0 mestre, naquele sadismo doentio de que falam Raul Pompeia e Gilberto Freyre, só se preocupava com embaraçar, humilhar, vilipendiar o estudante. Professava o mais soberano despreso pelo animal-aluno, e exultava de gozo quando, ao fim do ano, conseguia reprovar a metade da turma.

O aluno, por sua vez, em justa represália, não cuidava senão de judiar do mestre, irritá-lo, ridicularizá-lo, enganálo nos exames. Chegava a odiá-lo, a êle e à sua disciplina.

Hoje, felizmente, é outra a atmosfera. Refresca-se o ambiente das escolas por eflúvios espirituais sadios e estimulantes, impregnados de reciproca simpatia. Compreen- 
demo-nos melhor, e, porque nos compreendemos, sabemos perdoar uns aos outros as fraquezas inevitáveis, para que só realcem as virtudes. Mestres e discipulos, sentimo-nos estreitamente unidos, como membros desta imensa fraternidade intelectual, que combate, na glória serena da paz, para o advento de um mundo melhor, mais justo, mais livre, mais humano.

Dentro, pois, dêsse espírito de harmonia e dêsse anceio de trabalho em comum, iniciemos, meus caros amigos, o ano letivo de 1942. 